\title{
Research and Discussion on the Influence of Network Economy on International Economy and Trade
}

\author{
Lan Wu \\ Chongqing Vocational Institution of Engineering, Chongqing 402260, China
}

Keywords: Network economy; International economic trade; Influence;

Abstract: Under the background of the rapid development of information technology, China's socialist market economy is also advancing rapidly. In this process, it is inseparable from the effective promotion of information technology. Internet technology brings us into the era of big data. In the process of economic production, more emphasis is placed on the application of big data and other information technologies, hoping to improve economic efficiency and thus remain invincible in the market environment. Such development momentum is powerful for social and economic development. The opportunity is undoubtedly a new challenge for the traditional international economy and trade. To address this issue, it is necessary to pay attention to the impact of the network economy on itself in the process of international economic and trade development. On this basis, it formulates a targeted response plan. To achieve international economic and trade reforms and form strategic measures suitable for China's social and economic development, this paper mainly analyzes the topic of the impact of the network economy on international economic trade, and then proposes the corresponding economy and thinking.

\section{Introduction}

In recent years, people's production and life have been used to realize the necessity and importance of applying network technology and information technology. With the improvement of thinking consciousness, it has also injected power into the popularization of network technology and information technology. The network economy began. In the world economy, it has emerged. According to reliable data, the scale of the global network economy has increased from more than one billion US dollars in the 1990s to more than 30 billion US dollars in the early 21st century. Such development momentum is undoubtedly a huge challenge for the development of traditional international economic trade. It is required that all countries in the world must pay attention to the construction of the network economy, and combine the current new development situation to clarify the impact of the network economy on the international economy. Based on this, we can formulate highly targeted measures.

\section{Overview of the network economy}

With the rapid development of information technology, the network economy has attracted people's attention. At this stage, it has also become a new economic form. The formation of this 
economic form is mainly based on the use of computer network technology, based on this, the economic form formed. The network economy can be described as a high-tech industry that has developed in recent years. It also contains traditional industries that design and apply high technology. Therefore, the network economy does not refer to the virtual economy that is not related to the traditional economy, but is based on the new form developed by the traditional economy. In the process of evolution, information technology is taken as the core, and the application ability of information technology is improved. Realized the reform and innovation of the traditional economy. It is worth mentioning that the rapid development of the network economy in recent years has brought many challenges to the contemporary economy, requiring the modern economy to achieve revolutionary changes in order to cope with challenges and achieve long-term development. At present, some enterprises in the world have fully utilized the network to strengthen enterprise management, resource integration and product marketing, etc., and the author also summarizes the main components of the network economy for the production and sales models of these enterprises. Logistics, information flow and capital flow. The network economy has changed the development concept of the traditional economy and reformed the previous economic development model. Especially with the rapid advancement of the global information network, the network has been popularized around the world, which makes information resources sharing and dissemination faster, and has injected a steady stream of power for the development of the network economy ${ }^{[1]}$. Under this new era development situation, it is necessary for the production economy to evolve and over-examine the knowledge economy. In the future, the network economy will occupy an important position in the global economy and even become a core content. It can be seen that the network economy has had a huge impact on international economic trade. Therefore, we must also face this influence. Next, the author analyzes the impact of the network economy on international economic trade.

\section{The impact of the network economy on international economic trade}

The emergence of Internet technology has led people into a new era. People in this new era have reformed the traditional economic development model, which has accelerated the pace of economic development and brought higher economic benefits to people. The development of the network economy has brought many influences on international economic and trade. Even if it puts forward rigid requirements for international economic trade, it must make reforms and innovations, keep pace with the development of the times, and optimize the economic structure so that it can be in the market economy. Realize long-term development under the big environment. According to the author's analysis, the impact of the network economy on international economic trade can be divided into two aspects: positive impact on the one hand and negative impact on the other. See below for details.

\subsection{Positive impact}

First, it has reduced trade barriers and laid the foundation for China's economic development. In the past international trade exchanges, China has been affected by trade barriers in many other countries, resulting in the extremely slow development of China's international trade. However, the promotion of network technology has made China's e-commerce rapid progress. The impact of e-commerce has weakened the impact of trade barriers and eased the seriousness of this problem. As we all know, the network has the characteristics of openness, while China is developing international trade. In the process of using the network to open up China's products to the world, showing the application advantages of China's products, which has subtly improved the competitiveness of Chinese enterprises, and also improved consumer satisfaction, and promoted a qualitative leap in 
China's economic and trade ${ }^{[2]}$.

Second, it has reduced the cost of international economic and trade, and at the same time increased operational efficiency. In the past, the international economic and trade development model, when conducting international trade, will go through a number of procedures and steps, including document communication, exchange, and contract signing. In addition, it must be delivered to consumers in a timely manner. Otherwise, it will greatly reduce consumer satisfaction ${ }^{[3]}$. However, it is worth mentioning that the rapid development of the network economy makes the contract paperless, and the data information involved in the economic and trade development can be processed through the network, and the use of e-mail to ensure the real-time transmission and sharing of data information. It can be seen that the use of network technology can reduce the capital investment in the international economic and trade development links to a certain extent, thereby reducing the cost of international trade, reducing the process in the trade process, eliminating unnecessary troubles, and simply feeding the products directly. In the hands of consumers, the efficiency of trade has been greatly improved.

Third, open up the global market and make the form of international trade more diversified. The past international trade pattern is subject to space and time constraints and is adversely affected by many factors. However, with the continuous implementation of network information technology, this situation has also undergone a tremendous transformation. In the process of international economic trade, it is only necessary to use the network approach to connect the global market as a whole, the time of breakthrough and the geographical Restrictions, every company in the world can participate in the community of economic interests, and ultimately obtain the corresponding economic benefits. In addition, the rapid development of information technology will also lead to a new type of trade model, for example, the current e-commerce. People can use the online shopping platform to use electronic money to pay, play the role of virtual network, complete virtual negotiations, then publish advertising and related information, increase publicity, attract more customers, expand consumer scale, and enhance enterprises. The overall strength ${ }^{[4]}$.

\subsection{Negative impact}

First, the lack of domestic e-commerce talent. The rapid development of e-commerce is inseparable from the strong support of human resources. In particular, every link in the development of e-commerce requires network operations. Many of these operations are relatively high-end, which requires enterprises to hire relevant electronic Business professionals, to complete business operations, with the continuous development of China's e-commerce, will increase the demand for related talents. However, according to reliable data, the employment rate of graduates of e-commerce majors in many colleges and universities in China cannot be improved or even in a downturn. This development situation has a great contradiction with the rapid development of the network economy. One of the problems ${ }^{[5]}$.

Second, it raises the risk of international trade. When people use the Internet to shop, they are accompanied by many security threats and even face many hidden dangers. Many secrets in international economic and trade links are easily stolen and vulnerable to hackers. It is likely to reveal customers' personal privacy. In addition, it directly affects national economic security. In addition, Internet crimes have been increasing in recent years. Therefore, in the process of developing the network economy, it is necessary to make timely compensation for network loopholes and do a good job in network prevention. However, such a treatment still cannot ensure that the development of the network economy is not threatened ${ }^{[6]}$. 


\section{In this information age, China's international economic and trade response measures}

\subsection{Objectively understanding the network economy and focusing on promoting online trade}

Under the background of this informationization, people's production and life are inseparable from the strong support of network technology. Therefore, in the process of China's international trade development, we should first position ourselves and face the development of the network economy. As an important factor in economic growth, the implementation of online trade is the basic requirement of the current national economic strategy. Therefore, it is necessary to provide enterprises with preferential policies to help enterprises use network technology to expand the scale of foreign trade, reduce operating costs, and improve economic efficiency. In this process, it is necessary to draw on the management experience of western developed countries, clarify the advantages of production technology application, and improve the competitiveness of enterprises. In the development of the network economy, we must also attach importance to resource integration, expand sales channels, give play to the advantages of China's foreign trade, and encourage small and medium-sized enterprises to participate in it, giving certain support, thus promoting the steady development of China's trade ${ }^{[7]}$.

\subsection{Paying attention to personnel training and speeding up the process of informationization}

Under the background of the rapid development of international economic and trade, all enterprises have increased their demand for talents in the development of foreign trade economy. Especially in the current era of vigorously promoting the network economy, the demand for e-commerce talents has only increased. It is necessary to strengthen the training of talents, inject talents into relevant enterprises, thereby enhancing the core competitiveness of enterprises, and accomplishing various tasks such as sales and promotion of products through network channels, reflecting the informationization and modernization features of enterprise operation and development.

\subsection{Establish an e-commerce platform suitable for the development of China's international trade}

Over the years, China's communication platform used in the process of developing international economic trade has been led by the United States and controlled by other countries. As a developing country, China lacks an effective opportunity to speak. However, since entering the 21st century, China's comprehensive strength has been continuously enhanced, and it has naturally improved its position in international economic trade. Therefore, we must seize the opportunity, face the challenges positively, take the initiative to participate in the international economic and trade environment, obtain effective power, and make reasonable speeches, resolutely resist other countries' trade barriers to China, thereby reducing the impact on China's international trade ${ }^{[8]}$.

\section{Conclusion}

In summary, this paper mainly analyzes the concept of network economy, and then discusses the impact of network economy on international economic trade, which can be divided into positive and negative effects, and finally puts forward countermeasures in the process of developing international economic trade. Hope can bring reference and reference to relevant researchers and accelerate the process of China's international trade reform. 


\section{Acknowledgement}

This work was supported by the "Project Name Social Relationship Network Impact on Residents' Income Gap”, Project No.: 17SKG277 Chongqing Humanities and Social Sciences Research Project.

\section{References}

[1] He Sijing. On the Influence of Network Economy on International Economic Trade. Knowledge Economy,Vol. 23 (2017) No.3, p.39, 41.

[2] Zhang Jun. Research and Analysis of the Influence of Network Economy on International Economic Trade. Modern Economic Information, Vol. 13 (2015) No.7, p.182-182.

[3] Shi Runan, Yuan Yushun. Research on the Influence of Network Economy on International Economy and Trade. Financial Economy (Theoretical Edition), Vol. 16 (2014) No.11, p.33-35.

[4] Zhu Jun. Analysis of the Influence of Network Economy Development on China's International Economic Trade. Discipline-Electronic Edition (Mid),Vol.21 (2016) No.3, p.116-116.

[5] Lu Wei. Analysis of the Influence of Network Economy on International Economy and Trade. Oriental Enterprise Culture,Vol. 19 (2015) No.18, p.260-260.

[6] Yuan Wanming. Exploring the influence of network economy on international economy and trade. Global Market,Vol. 29 (2018) No.16, p.137, 144.

[7] Xie Kanghua. Research on the Influence of Network Economy on International Economy and Trade. Shang,Vol. 22 (2016) No.10, p.126.

[8] Dai Bin. Research on the Influence of Network Economy on China's International Trade. Shopping Mall Modernization, Vol. 32 (2015) .No.27, p.3-4. 